\title{
Synthesis and Optical Properties of II-O-VI Highly Mismatched Alloys
}

\author{
K. M. Yu, W. Walukiewicz, W. Shan, J. Wu, and J. W. Beeman, \\ Materials Sciences Division, Lawrence Berkeley National Laboratory, Berkeley, \\ California 94720 \\ M. A. Scarpulla, O. D. Dubon \\ Materials Sciences Division, Lawrence Berkeley National Laboratory, and Department \\ of Materials Sciences and Mineral Engineering, University of California, Berkeley, \\ California 94720 \\ P. Becla \\ Department of Materials Science and Engineering, Massachusetts Institute of \\ Technology, Cambridge, Massachusetts 02139
}

\begin{abstract}
We have synthesized ternary and quaternary diluted II-VI oxides using the combination of $\mathrm{O}$ ion implantation and pulsed laser melting. $\mathrm{CdO}_{\mathrm{x}} \mathrm{Te}_{1-\mathrm{x}}$ thin films with $\mathrm{x}$ up to 0.015 , and the energy gap reduced by $150 \mathrm{meV}$ were formed by $\mathrm{O}^{+}$-implantation in $\mathrm{CdTe}$ followed by pulsed laser melting. Quaternary $\mathrm{Cd}_{0.6} \mathrm{Mn}_{0.4} \mathrm{O}_{\mathrm{x}} \mathrm{Te}_{1-\mathrm{x}}$ and $\mathrm{Zn}_{0.88} \mathrm{Mn}_{0.12} \mathrm{O}_{\mathrm{x}} \mathrm{Te}_{1-\mathrm{x}}$ with mole fraction of incorporated $\mathrm{O}$ as high as 0.03 were also formed. The enhanced $\mathrm{O}$ incorporation in Mn-containing alloys is believed to be due to the formation of relatively strong Mn-O bonds. Optical transitions associated with the lower $\left(E_{-}\right)$and upper $\left(E_{+}\right)$ conduction subbands resulting from the anticrossing interaction between the localized $\mathrm{O}$ states and the extended conduction states of the host are clearly observed in these quaternary diluted II-VI oxides. These alloys fulfill the criteria for a multiband semiconductor that has been proposed as a material for making high efficiency, singlejunction solar cells.
\end{abstract}

PACS numbers: 71.20.Nr; 78.66.Hf; 61.72.Vv; 61.80.Ba 


\section{INTRODUCTION}

Group II-O-VI alloys belong to a new class of semiconductor alloys in which the anions are partially replaced by highly electronegative isoelectronic $\mathrm{O}$ atoms. As expected these alloys have properties similar to the extensively studied group III-N-V alloys [1-8]. The electronic band structure of such Highly Mismatched Alloys (HMAs) is determined by an anticrossing interaction between localized states of $\mathrm{O}$ or $\mathrm{N}$ and the extended states of the semiconductor matrix. The interaction splits the conduction band into two nonparobolic subbands $\left(E_{-}\right.$and $\left.E_{+}\right)$[9-11]. The large modification of the electronic band structure profoundly affects the optical and electrical properties of these alloys. Thus it has been shown that incorporation of small amount of $\mathrm{N}$ leads to a large reduction of the fundamental band gap [1-8], increase of the electron effective mass [12], improved donor activation efficiency of the group VI donors $[13,14]$ and the mutual passivation of the group IV donors and the nitrogen [15-18]. Although similar or even more pronounced effects are also expected in II-O-VI HMAs [10], much less work has been done on these materials because of the difficulties in the synthesis of the alloys with large enough O content $[19,20]$.

Recently we have reported on the successful synthesis of $\mathrm{Cd}_{1-\mathrm{y}} \mathrm{Mn}_{\mathrm{y}} \mathrm{O}_{\mathrm{x}} \mathrm{Te}_{1-\mathrm{x}}$ alloys by oxygen implantation into $\mathrm{Cd}_{1-\mathrm{y}} \mathrm{Mn}_{\mathrm{y}}$ Te crystals followed by rapid thermal annealing (RTA) [21]. We observed a large decrease in the band gap for crystals with $y>0.02$ due to the incorporation of $\mathrm{O}$. Using the band anticrossing model (BAC) we estimated that the substitutional $\mathrm{O}$ content (i.e., $x$ ) in the $\mathrm{Cd}_{0.8} \mathrm{Mn}_{0.2} \mathrm{O}_{x} \mathrm{Te}_{1-x}$ alloys formed by $\mathrm{O}^{+}-$ implantation is $\sim 0.0013$ and 0.0024 for 2.7 and $5.4 \%$ of implanted $\mathrm{O}$, respectively. This 
corresponds to an "activation" efficiency (i.e., ratio of the $\mathrm{O}$ ions occupying substitutional Te sites to the total implanted O) of only about $5 \%$. Moreover, no reduction in the band gap was observed for samples without $\mathrm{Mn}(\mathrm{y}=0)$. It was argued that $\mathrm{Mn}$ is needed to stabilize incorporation of substitutional $\mathrm{O}$ possibly through the formation of relatively strong Mn-O bonds [21].

In a recent report, we have demonstrated that pulsed laser melting (PLM) followed by rapid thermal annealing greatly enhanced incorporation of substitutional $\mathrm{N}$ in $\mathrm{N}^{+}$-implanted GaAs $[22,23]$. Films implanted to $1.8 \% \mathrm{~N}$ exhibited a fundamental band gap of $1.26 \mathrm{eV}$ (a band gap reduction of $160 \mathrm{meV}$ ), corresponding to an $\mathrm{N}$ activation efficiency of 50\%. The optical and crystalline quality of the synthesized film is comparable to $\mathrm{GaN}_{\mathrm{x}} \mathrm{As}_{1-\mathrm{x}}$ thin films of similar composition grown by epitaxial growth techniques. Compared to films produced by $\mathrm{N}^{+}$implantation and rapid thermal annealing only, the introduction of pulsed laser annealing improved $\mathrm{N}$ incorporation by a factor of five [24].

Pulsed laser melting (PLM) of ion implanted Si and GaAs was studied extensively in the 1970s and 1980s $[25,26]$. It involves the absorption of laser radiation, melting of the implant-damaged or amorphized, and its subsequent rapid epitaxial regrowth. Epitaxy is seeded at the solid-liquid interface by the crystalline bulk in a manner very similar to liquid phase epitaxy (LPE) but with the whole process occurring on a much shorter time scale, typically between $10^{-8}-10^{-6}$ second. It was shown that using the PLM method amorphous layers of GaAs formed by high dose implantation can be regrown into nearly perfect single crystals with electrical activities of dopants well above those achievable by furnace annealing [26]. Due to the rapid recrystallization rate, this 
approach is very effective for incorporating impurities to levels well above the solubility limit. In addition to $\mathrm{GaN}_{\mathrm{x}} \mathrm{As}_{1-\mathrm{x}}$, synthesis of diluted ferromagnetic $\mathrm{Ga}_{1-\mathrm{x}} \mathrm{Mn}_{\mathrm{x}} \mathrm{As}$ with Curie temperature as high as $80 \mathrm{~K}$ using the PLM process has recently been demonstrated [27]. In this paper we report our systematic investigation of the synthesis of II- $\mathrm{O}_{\mathrm{x}} \mathrm{VI}_{1-\mathrm{x}}$ layers using $\mathrm{O}$ ion implantation followed by pulsed laser melting in a large variety of IIVI single crystal substrates, including CdTe, CdMnTe, ZnTe and ZnMnTe.

\section{EXPERIMENTAL}

Multiple energy implantation with 90 and $30 \mathrm{keV} \mathrm{O}$ ions was carried out on various II-VI single crystals to form $\sim 0.2 \mu \mathrm{m}$ thick layers with relatively constant initial $\mathrm{O}$ concentrations, corresponding to $\mathrm{O}$ mole fraction of 0.01 to 0.04 (or 1 to $4 \%$ ). The $\mathrm{O}^{+}$implanted layers on the crystals were pulsed-laser melted in air using a $\mathrm{KrF}$ laser $(\lambda=248$ $\mathrm{nm}$ ) with a FWHM pulse duration $\sim 38 \mathrm{~ns}$. After passing through a multi-prism homogenizer, the energy fluence at the sample ranged between 20 and $300 \mathrm{~mJ} / \mathrm{cm}^{2}$. Some of the samples were rapid thermally annealed after the PLM process at temperatures between 300 and $600^{\circ} \mathrm{C}$ for 10 seconds (RTA) in flowing $\mathrm{N}_{2}$.

The band gap of the synthesized layers was measured using photomodulated reflectance (PR) spectroscopy at room temperature. Radiation from a $300 \mathrm{~W}$ halogen tungsten lamp dispersed by a $0.5 \mathrm{~m}$ monochromator was focused on the samples as a probe beam. A chopped $\mathrm{HeCd}$ laser beam ( $\lambda=442 \mathrm{~nm}$ or $325 \mathrm{~nm})$ provided the photomodulation. PR signals were detected by a Si or Ge photodiode using a phasesensitive lock-in amplification system. The values of the band gap and the linewidth 
were determined by fitting the PR spectra to the Aspnes third-derivative functional form [28]. The effects of applied pressure on the $E_{-}$transition in the $\mathrm{Zn}_{0.88} \mathrm{Mn}_{0.12} \mathrm{O}_{\mathrm{x}} \mathrm{Te}_{1-\mathrm{x}}$ were studied in order to verify the origin of the $E_{-}$band. Application of hydrostatic pressure was accomplished by mounting small sample chips with sizes of $\sim 200 \times 200 \mu \mathrm{m}^{2}$ into gasketed diamond anvil cells while the optical transitions in the samples were measured by photomodulated transmission (PT) [9].

\section{RESULTS AND DISCUSSION}

\section{(i) $\mathrm{Cd}_{1-y} \underline{\mathrm{O}}_{x} \underline{\mathrm{Te}_{1-x}} \underline{\mathrm{HMAs}}$}

Figure 1 shows a series of PR spectra from CdTe samples unimplanted and implanted with 4 mole $\%$ of $\mathrm{O}^{+}$followed by rapid thermal annealing in the temperature range of $300-500^{\circ} \mathrm{C}$ for $10 \mathrm{~s}$. No optical transition can be observed for the $\mathrm{O}^{+}$-implanted sample without RTA. This is attributed to the lattice damage due to the large $\mathrm{O}$ dose implanted in the CdTe. A distinct transition feature at around the CdTe band gap (1.51 $\mathrm{eV}$ ) is observed in $\mathrm{O}^{+}$-implanted samples after RTA at temperatures higher than $300^{\circ} \mathrm{C}$. The linewidth of the main transition improves as the RTA temperature increases due to the removal of implantation-induced crystalline defects in the samples. For all the CdTe samples implanted with $\mathrm{O}^{+}$followed by RTA, no significant band gap reduction can be observed. This indicates that the implanted $\mathrm{O}$ does not reside in the Te sublattice, but possibly agglomerates to form $\mathrm{O}$ bubbles, similar to the case of $\mathrm{N}_{\text {in }} \mathrm{N}^{+}$implanted GaAs after RTA at temperatures higher than $950^{\circ} \mathrm{C}[29]$. 
Results of PR measurements on $\mathrm{O}^{+}$-implanted CdTe samples (with implanted $\mathrm{O}$ corresponding to 0 to 4 mole \%) followed by PLM with an energy fluence of $40 \mathrm{~mJ} / \mathrm{cm}^{2}$ are shown in Fig. 2. PR spectra from a CdTe substrate and an unimplanted CdTe treated with the PLM process $(0 \% \mathrm{O})$ are also included for direct comparison. A large band gap reduction $(\Delta \mathrm{E})$ is immediately evident in the $\mathrm{O}^{+}$-implanted CdTe samples after PLM. For the CdTe sample implanted with $2 \%$ of $\mathrm{O}$ after PLM, the fundamental gap is $1.37 \mathrm{eV}$, corresponding to a band gap reduction $\Delta \mathrm{E}=140 \mathrm{meV}$. This large reduction in the bandgap is a clear indication of $\mathrm{O}$ incorporation in the Te sublattice, forming $\mathrm{CdO}_{\mathrm{x}} \mathrm{Te}_{1-\mathrm{x}}$ alloys. Contrary to the case of PLM of $\mathrm{N}^{+}$-implanted GaAs where an optical transition can only be observed after RTA following PLM [22, 23], $\mathrm{O}^{+}$-implanted CdTe samples show clear, sharp optical transitions after PLM without additional thermal annealing. This can be attributed to the higher resistance of CdTe (and II-VI alloys in general) to the formation of structural defects due to the more ionic nature of the crystals.

Fig. 2 also shows that the band gap reduction (or $\mathrm{O}$ incorporation) increases as the implanted $\mathrm{O}$ content increases from 1 to $2 \%$. However, a further increase in the implanted $\mathrm{O}$ concentration leads to a saturation of the band gap at $\sim 1.37 \mathrm{eV}$. This suggests that there is a maximum in the amount of $\mathrm{O}$ that can be incorporated in the Te sublattice in CdTe under the present PLM conditions. Notice that there is no reduction in the band gap energy for an unimplanted CdTe sample after PLM $(0 \%$ O). This demonstrates that the band gap reduction arises from the $\mathrm{O}$ incorporation in the $\mathrm{Te}$ sublattice but not from the laser melting process.

Fig. 3 summarizes the band gap energies of the $\mathrm{CdO}_{\mathrm{x}} \mathrm{Te}_{1-\mathrm{x}}$ alloys formed by $\mathrm{O}^{+}-$ implantation in CdTe followed by PLM with laser energy fluence in the range of 40 to 
$100 \mathrm{~mJ} / \mathrm{cm}^{2}$ as a function of the implanted $\mathrm{O}^{+}$concentration. We point out that no band gap reduction is found in $\mathrm{O}^{+}$-implanted CdTe followed by PLM with energy fluence lower than $30 \mathrm{~mJ} / \mathrm{cm}^{2}$, suggesting that under the present PLM conditions the melting threshold of CdTe is $\sim 40 \mathrm{~mJ} / \mathrm{cm}^{2}$. The result is consistent with the recently reported melting threshold energy fluence for CdTe determined by time resolved reflectivity (TRR) [30].

For $\mathrm{O}^{+}$-implanted CdTe samples PLM at 40 and $60 \mathrm{~mJ} / \mathrm{cm}^{2}$, the band gap follows a similar trend. It is reduced for the implanted $\mathrm{O}$ range from $1 \%$ to $2 \%$ and then it saturates at $\sim 1.37 \mathrm{eV}$ when more $\mathrm{O}$ atoms is introduced into the substrate. This saturation can be attributed to the $\mathrm{O}$ content exceeding the kinetic solubility limit even for the short melt duration of $\sim 300$ nsec. On the other hand, the band gap of samples melted at energy fluence higher than $60 \mathrm{~mJ} / \mathrm{cm}^{2}$ becomes insensitive to the total implanted $\mathrm{O}$ dose. Moreover, for fixed implanted $\mathrm{O}$ content, we observe a monotonic decrease in the band gap reduction of CdTe samples as the PLM energy fluence increases. This indicates that less $\mathrm{O}$ is incorporated in the Te sublattice as the $\mathrm{O}^{+}$-implanted CdTe samples are exposed to laser pulse with higher energy fluences. This can be understood since increasing the energy fluence increases the melt depth in the sample and consequently also prolongs the duration of the melt/crystallization process, driving the system closer to the equilibrium state. This suggests that the $\mathrm{Cd}-\mathrm{O}$ bonding in the $\mathrm{CdO}_{\mathrm{x}} \mathrm{Te}_{1-\mathrm{x}}$ alloy is relatively weak and an increase in the melt duration for higher energy fluence enables the $\mathrm{O}$ atoms to move out of the Te sublattice, thus decreasing the $\mathrm{O}$ incorporation in the alloy. For CdTe implanted with 1 to $4 \%$ of $\mathrm{O}$ and irradiated with energy fluence greater 
than $150 \mathrm{~mJ} / \mathrm{cm}^{2}$, no band gap reduction was detected. This is consistent with the reported ablation threshold of $\sim 0.12 \mathrm{~J} / \mathrm{cm}^{2}$ for CdTe using a $248 \mathrm{~nm} \mathrm{KrF}$ laser pulse [30].

The amount of $\mathrm{O}$ incorporated in the Te sublattice in $\mathrm{CdO}_{\mathrm{x}} \mathrm{Te}_{1-\mathrm{x}} \mathrm{HMAs}$ can be determined using the band anticrossing (BAC) model [9-11]. As mentioned above, the physical basis for the BAC model is a repulsive interaction between the localized level introduced by the highly electronegative impurities and the extended states of the conduction band of the host. According to the BAC model the dispersion relations for the upper $\left(E_{+}\right)$and lower $\left(E_{-}\right)$conduction subbands in a $\mathrm{IIO}_{\mathrm{x}} \mathrm{VI}_{1-\mathrm{x}} \mathrm{HMAs}$ are given by [911]

$$
E_{ \pm}(k)=\frac{1}{2}\left[E_{O}+E_{M}(k) \pm \sqrt{\left(E_{O}-E_{M}(k)\right)^{2}+4 C_{O M}^{2} x}\right]
$$

where $E_{O}$ is the energy of the localized $\mathrm{O}$ level, $E_{M}(\mathrm{k})$ is the dispersion relation for the conduction band of the host semiconductor, and $C_{O M}$ is the matrix element describing the coupling between localized $\mathrm{O}$ states and the extended states. Photoluminescence spectroscopy (PL) studies in ZnTe have shown that at low, impurity-like concentrations, oxygen forms a localized level in the gap with an energy $E_{O}=2.0 \mathrm{eV}$ above the valence band edge [31]. It has been shown previously that the energy of the oxygen level, $E_{O}$ is constant in the absolute energy reference [10]. Therefore with the known band offsets between $\mathrm{ZnTe}$ and CdTe the localized O level in CdTe has been determined to be $\sim 1.9$ $\mathrm{eV}$ above the CdTe valence band maximum [21].

In the case of II-VI alloys the matrix element $C_{O M}$ was measured in $\mathrm{ZnSe}_{x} \mathrm{Te}_{1-x}$ and $\mathrm{ZnS}_{y} \mathrm{Te}_{l-y} \mathrm{HMAs}$ to be $1 \mathrm{eV}$ [10]. In a recent report, Shan et al. studied the composition and pressure dependence of the electronic band structure of $\mathrm{ZnO}_{\mathrm{x}} \mathrm{Se}_{1-\mathrm{x}}$ alloys 
grown by molecular beam epitaxy [20]. By fitting of the optical transitions with the BAC model, they found that the interaction parameter $C_{O M}=1.8 \pm 0.3 \mathrm{eV}$ for $\mathrm{ZnO}_{\mathrm{x}} \mathrm{Se}_{1-\mathrm{x}}$. In this work $C_{O M}$ cannot be determined independently because a precise measurement of the fraction of $\mathrm{O}$ on the Te sublattice (i.e., $x$ ) is not possible. It is, however, believed that the magnitude of this matrix element depends on the electronegativity difference between the matrix anion elements [10]. From the dependence of the $C_{O M}$ in the various II-VI HMA systems on the anion electronegativity difference, we make the reasonable assumption that $C_{O M} \approx 2.2 \mathrm{eV}$ in $\mathrm{CdO}_{\mathrm{x}} \mathrm{Te}_{1-\mathrm{x}}$. Notice that this $C_{O M}$ is much smaller than the value (3.5 $\mathrm{eV})$ we used in our previous work $[21,32]$. This previous high value of $C_{O M}$ was extrapolated from the matrix elements $C_{N M}$ in III-N-V HMAs $\left(\mathrm{GaN}_{\mathrm{x}} \mathrm{As}_{1-\mathrm{x}}\right.$ and $\left.\mathrm{InN}_{\mathrm{x}} \mathrm{P}_{1-\mathrm{x}}\right)$ and therefore may not apply in II-O-VI systems.

Using the estimated $C_{O M}$ value of $2.2 \mathrm{eV}$ and equation (1), the "active" O mole fractions incorporated in the Te sublattice for $\mathrm{CdO}_{\mathrm{x}} \mathrm{Te}_{1-\mathrm{x}} \mathrm{HMAs}$ using a laser fluence of 40 and $80 \mathrm{~mJ} / \mathrm{cm}^{2}$ as a function of implanted $\mathrm{O}$ concentration are calculated and shown in Fig. 4. The $\mathrm{x}$ values shown in Fig. 4 reveal that for the lower implanted $\mathrm{O}^{+}$concentration of $1 \%$ the $\mathrm{O}$ activation efficiency is close to $100 \%$. Moreover, the kinetic limit of solubility of O in CdTe for PLM at $40 \mathrm{~mJ} / \mathrm{cm}^{2}$ is $\sim 0.015$. For a PLM fluence of 80 $\mathrm{mJ} / \mathrm{cm}^{2}$ this limit decreases to $\sim 0.01$ because of the prolonged melt/crystallization duration. This is in agreement with our previous report on the synthesis of $\mathrm{GaN}_{\mathrm{x}} \mathrm{As}_{1-\mathrm{x}}$ where we found that increasing the energy fluence results in a decrease in the band gap reduction and correspondingly a decrease in the amount of incorporated $\mathrm{N}$ [23].

Fig. 5 shows a series of PR spectra from the $2 \% \mathrm{O}^{+}$-implanted CdTe samples after PLM at $40 \mathrm{~mJ} / \mathrm{cm}^{2}$ followed by RTA for $10 \mathrm{~s}$ at temperatures of 300 and $400^{\circ} \mathrm{C}$. A 
reduction in the energy shift of the fundamental gap can be observed at RTA temperature higher than $300^{\circ} \mathrm{C}$. This again suggests that the $\mathrm{Cd}-\mathrm{O}$ bonds are relatively weak and the $\mathrm{CdO}_{\mathrm{x}} \mathrm{Te}_{1-\mathrm{x}}$ alloys formed by implantation and PLM are thermally unstable. At an RTA temperature of $400^{\circ} \mathrm{C}$, only the original $\mathrm{E}_{\mathrm{M}}$ transition is observed. This may reflect that most of the implanted $\mathrm{O}$ atoms that resided in the Te sites after PLM diffused out of the Te sites, possibly forming $\mathrm{O}$ bubbles.

\section{(ii) II-Mn-O-VI Quaternary Alloys}

It follows from the BAC model that when the localized state is located within the conduction band of the matrix, as in the case of $\mathrm{O}$ in CdTe and $\mathrm{N}$ in GaAs, the conduction-band states associated with the $E_{-}$edge retain the extended $E_{M^{-}}$-like character and those at the $E_{+}$edge have a more localized $E_{O}$-like character. For all the $\mathrm{CdO}_{\mathrm{x}} \mathrm{Te}_{1-\mathrm{x}}$ alloys synthesized by ion implantation and PLM, no $E_{+}$transition has been observed in our optical measurements. This can be explained by the fact that the $E_{+}$subband edge is formed from states of largely localized-like character; since the dipole interaction for optical transitions couples much more strongly to extended states than localized ones, the transition related to $E_{+}$is inherently weak. For the case of the localized states lying below the conduction-band edge, the conduction-subband edges of $E_{-}$and $E_{+}$switch character: the $E_{-}$subband states are of highly localized character and the $E_{+}$subband states become more extended. This latter situation occurs for $\mathrm{O}$ in $\mathrm{ZnTe}, \mathrm{MnTe}$ and $\mathrm{Cd}_{1-}$ y $\mathrm{Mn}_{\mathrm{y}} \mathrm{Te}$ with $\mathrm{y} \geq 0.4$.

Fig. 6 shows PR spectra of two $4 \% \mathrm{O}^{+}$-implanted $\mathrm{Cd}_{1-\mathrm{y}} \mathrm{Mn}_{\mathrm{y}}$ Te samples with $\mathrm{y}=0$ and 0.4 , respectively followed by PLM. PR spectra of the original $\mathrm{Cd}_{1-\mathrm{y}} \mathrm{Mn}_{\mathrm{y}} \mathrm{Te}$ substrates 
are also shown for comparison. While only a relatively small reduction in the band gap $(\sim 130 \mathrm{meV})$ is visible for the $\mathrm{CdO}_{\mathrm{x}} \mathrm{Te}_{1-\mathrm{x}}$ layer, corresponding to $\mathrm{x} \sim 0.012$, a large band gap reduction of $\sim 400 \mathrm{meV}$ is observed for the $\mathrm{Cd}_{0.6} \mathrm{Mn}_{0.4} \mathrm{O}_{\mathrm{x}} \mathrm{Te}_{1-\mathrm{x}}$ layer. Using the same assumption of $C_{O M}=2.2 \mathrm{eV}, \mathrm{x}$ is estimated to be 0.029 . In addition, another transition at $\sim 2.45 \mathrm{eV}$ is also observed in this sample. This high energy transition corresponds to the optical transition from the valence band to the upper conduction subband $E_{+}$for a $\mathrm{Cd}_{0.6} \mathrm{Mn}_{0.4} \mathrm{O}_{\mathrm{x}} \mathrm{Te}_{1-\mathrm{x}}$ layer with $\mathrm{x} \sim 0.029$. Fig. 6 clearly shows that Mn leads to increased incorporation of substitutional $\mathrm{O}$ on the Te sublattice of $\mathrm{CdTe}$. This can be attributed to the formation of relatively strong $\mathrm{Mn}-\mathrm{O}$ bonds. We also note that $E_{O}$ for a $\mathrm{Cd}_{0.6} \mathrm{Mn}_{0.4} \mathrm{Te}$ crystal is at $2.06 \mathrm{eV}$ while the fundamental band gap transition $E_{M}$ is at $2.10 \mathrm{eV}$, corresponding to the case when the $E_{O}$ is below the conduction band minimum of the host and therefore the $E_{+}$subband states attain more of the extended-like character.

Fig. 7 shows the PR spectra of $\mathrm{Cd}_{0.6} \mathrm{Mn}_{0.4} \mathrm{O}_{\mathrm{x}} \mathrm{Te}_{1-\mathrm{x}}$ layers formed by $\mathrm{O}^{+}-$ implantation followed by either RTA or PLM as indicated. The PR spectra of the asgrown $\mathrm{Cd}_{0.6} \mathrm{Mn}_{0.4} \mathrm{Te}$ substrates are presented for reference. Notice the large band gap reduction in the sample treated with PLM as compared to the sample treated with RTA. The calculated values of $E_{-}$and $E_{+}$according to the BAC model [Equation (1)] as a function of $\mathrm{O}$ content $\mathrm{x}$ for $\mathrm{Cd}_{0.6} \mathrm{Mn}_{0.4} \mathrm{Te}$ are shown in the inset of Fig. 7 together with the data from the PR spectra shown in the figure. The positions of $E_{O}$ and $E_{M}$ are also indicated in the inset. Both the $E_{-}$and $E_{+}$values for the PLM and RTA samples agree with calculation. While only $\sim 0.3 \%$ of $\mathrm{O}$ substitutionally incorporated into the sample formed by RTA alone, as much as $2.95 \%$ of $\mathrm{O}$ is incorporated into the PLM sample. This high $\mathrm{O}$ activation efficiency is achieved due to the extremely short melt duration $(\sim 200$ 
nsec) and regrowth process that promotes $\mathrm{O}$ substitution in the Te sublattice and inhibits the formation of oxygen related voids. This is similar to our results on the formation of $\mathrm{GaN}_{\mathrm{x}} \mathrm{As}_{1-\mathrm{x}}$ by $\mathrm{N}^{+}$implantation and PLM [23, 29].

The $\mathrm{Zn}_{1-\mathrm{y}} \mathrm{Mn}_{\mathrm{y}}$ Te alloys represent another interesting case in which the localized oxygen level lies much below the conduction band minimum for the whole $\mathrm{Mn}$ composition range $(>200 \mathrm{meV})$. Fig. 8 shows a series of PR spectra from $\mathrm{Zn}_{0.88} \mathrm{Mn}_{0.12} \mathrm{Te}$ samples implanted with 3.3\% of O followed by PLM with laser energy fluence ranging from 0.04 to $0.3 \mathrm{~J} / \mathrm{cm}^{2}$. Two optical transitions in the vicinity of $\sim 1.8$ and $2.6 \mathrm{eV}$ are clearly observed from the samples after PLM with fluences $\geq 0.08 \mathrm{~J} / \mathrm{cm}^{2}$. These transitions occur at energies distinctly different from the fundamental band gap transition at $E_{M}=2.32 \mathrm{eV}$ of the $\mathrm{Zn}_{0.88} \mathrm{Mn}_{0.12}$ Te matrix. The results in Fig. 8 indicate that $\mathrm{Zn}_{0.88} \mathrm{Mn}_{0.12} \mathrm{O}_{\mathrm{x}} \mathrm{Te}_{1-\mathrm{x}}$ layers are formed in samples implanted with $\mathrm{O}^{+}$and irradiated with an energy fluence $\geq 0.08 \mathrm{~J} / \mathrm{cm}^{2}$. The two optical transitions can be attributed to the transitions from the valence band to the two conduction subbands, $E_{+}(\sim 2.6 \mathrm{eV})$ and $E_{-}$ $(\sim 1.8 \mathrm{eV})$ formed as a result of the hybridization of the localized $\mathrm{O}$ states and the extended conduction band states of ZnMnTe. We note that the observation of the strong photomodulated transition signals at both $E_{-}$and $E_{+}$indicates the extended nature of these electronic states and the substantial oscillator strength for the transitions. No optical transition is observed for the implanted samples with PLM fluence lower than $0.04 \mathrm{~J} / \mathrm{cm}^{2}$ indicating that the melting threshold for $\mathrm{ZnMnTe}$ is between 0.04 and $0.08 \mathrm{~J} / \mathrm{cm}^{2}$ using our laser.

The substitutional mole fractions of $\mathrm{O}$ for the $\mathrm{Zn}_{0.88} \mathrm{Mn}_{0.12} \mathrm{O}_{\mathrm{x}} \mathrm{Te}_{1-\mathrm{x}}$ layers synthesized by ion implantation and PLM shown in Fig. 8 are calculated using the BAC 
model with the assumed value of $C_{O M}=2.2 \mathrm{eV}$. For the sample irradiated with 0.15 $\mathrm{J} / \mathrm{cm}^{2}, \mathrm{x}$ is estimated to be $\sim 0.023$. The energy positions of $E_{-}$and $E_{+}$for the $\mathrm{Zn}_{0.88} \mathrm{Mn}_{0.12} \mathrm{O}_{x} \mathrm{Te}_{1-x}$ alloys with different $\mathrm{x}$ are plotted in Fig. 9. Data taken from samples implanted with different concentration of $\mathrm{O}(1.65,2.2$ and $4.4 \%)$ as well as PLM with different energy fluences are also plotted on Fig. 9. We note in Fig. 8 that $\mathrm{x}$ decreases with increasing energy fluence beyond $\sim 0.08 \mathrm{~J} / \mathrm{cm}^{2}$; possibly due to the longer melt duration and/or dilution through the deeper melt depth. This is in agreement with the discussed above results of the PLM fluence dependence of $\mathrm{O}$ incorporation in the $\mathrm{CdO}_{\mathrm{x}} \mathrm{Te}_{1-\mathrm{x}}$ samples. The energy positions of the two transitions as predicted by the $\mathrm{BAC}$ model are also plotted as solid lines. Given the broader linewidths of the $E_{+}$transitions, they agree reasonably well with the calculated values for samples with various $\mathrm{O}$ mole fractions.

The effects of applied pressure on the $E_{-}$transition in the $\mathrm{Zn}_{0.88} \mathrm{Mn}_{0.12} \mathrm{O}_{\mathrm{x}} \mathrm{Te}_{1-\mathrm{x}}$ samples were studied in order to verify the origin of the $E_{-}$subband. The energy positions of the $E_{-}$transition in the sample treated by PLM with a laser energy fluence of $0.3 \mathrm{~J} / \mathrm{cm}^{2}$ has been measured as a function of applied hydrostatic pressure at room temperature. The results are shown in Fig. 10, along with the measured pressure dependence of the band gap of $\mathrm{Zn}_{0.88} \mathrm{Mn}_{0.12} \mathrm{Te}$. The room-temperature energy $E_{+}$at atmospheric pressure is also shown in the figure. The inset shows a typical photomodulated transmission (PT) spectrum recorded at high pressures ( $4.7 \mathrm{kbar})$. The broad PT feature on the lower energy side corresponds to the $E_{-}$transition and the narrow PT feature $\left(E_{\mathrm{g}}^{\mathrm{ZnnnTe}}\right)$ on the higher energy side is the transition associated with the fundamental band gap of $\mathrm{Zn}_{0.88} \mathrm{Mn}_{0.12}$ Te substrate. 
By fitting the experimental data, represented by the open circle in Fig. 10 with the linear function we obtain the value of $\mathrm{d} E_{\mathrm{g}} / \mathrm{dP}=8.5 \mathrm{meV} / \mathrm{kbar}$ for the coefficient of the energy gap of $\mathrm{Zn}_{0.88} \mathrm{Mn}_{0.12} \mathrm{Te}$. Notice that the pressure-induced energy shift of the $E_{-}$ transition of $\mathrm{Zn}_{0.88} \mathrm{Mn}_{0.12} \mathrm{O}_{\mathrm{x}} \mathrm{Te}_{1-\mathrm{x}}$ is much weaker (initial slope $\approx 2 \mathrm{meV} / \mathrm{kbar}$ ) and nonlinear as compared to the change of the direct band gap of $\mathrm{Zn}_{0.88} \mathrm{Mn}_{0.12}$ Te. The weak pressure dependence of the $E_{-}$transition can be fully understood with the BAC model. The fact that $E_{-}$is located much closer to the energy level of the localized $O$ states gives its wavefunction a pronounced O-like character. The solid lines through the experimental data in Fig. 10 are the calculated pressure dependencies of $E_{-}$and $E_{+}$transitions using Eq. (1). The best fits to the data yield the energy position of the $\mathrm{O}$ level (relative to the top of the valence band) $E_{O}=E_{V}+2.0 \pm 0.1 \mathrm{eV}$ at atmospheric pressure with a pressure dependence of $0.6 \pm 0.1 \mathrm{meV} / \mathrm{kbar}$. It is clear from the figure that the pressure dependence of $E_{-}$is slightly stronger than that of the $\mathrm{O}$ level as expected from the admixture of extended conduction-band $\Gamma_{\mathrm{C}}$ states of the matrix to the $E_{-}$band-edge states. On the other hand, the much weaker pressure dependence of $E_{-}$as compared to that of the conduction-band $\Gamma_{\mathrm{C}}$ edge indicates the predominantly O-like nature of the $E_{-}$subband.

In addition to the unconventional conduction band structure this new diluted II-VI oxide represents an interesting case of a semiconductor with multiple direct gaps. Such semiconductors have been theoretically considered as materials for high efficiency single junction solar cells [33]. Detailed balance calculations have shown that a single junction cell with one and two properly located bands of intermediate states could achieve power conversion efficiencies up to $62 \%$ and $71.7 \%$, respectively [33,34]. Although deep impurity and defect states have been previously suggested for this purpose, no such 
materials have been ever practically realized due to the difficulties in controlling the position and concentration of such states.

The multiband $\mathrm{Zn}_{1-\mathrm{y}} \mathrm{Mn}_{\mathrm{y}} \mathrm{O}_{\mathrm{x}} \mathrm{Te}_{1-\mathrm{x}}$ alloys in which the interband transition energies can be controlled by the alloy composition are potential materials for such type of high efficiency solar cells. For a $\mathrm{Zn}_{0.88} \mathrm{Mn}_{0.12} \mathrm{O}_{\mathrm{x}} \mathrm{Te}_{1-\mathrm{x}}$ alloy with $\mathrm{x} \sim 0.023$ (sample PLM with $\left.0.15 \mathrm{~J} / \mathrm{cm}^{2}\right)$, the three absorption edges: $E_{+}(\mathrm{k}=0)-E_{V}(\mathrm{k}=0)=2.56 \mathrm{eV}, E_{-}(\mathrm{k}=0)-$ $E_{V}(\mathrm{k}=0)=1.83 \mathrm{eV}$ and $E_{+}(\mathrm{k}=0)-E_{-}(\mathrm{k}=0)=0.73 \mathrm{eV}$, span much of the solar spectrum. Calculations based on detailed balance theory [33-35] for this material yield an ideal power conversion efficiency of $45 \%$. This is higher than the ideal efficiency of any solar cell based on a single junction in a single-gap semiconductor and is comparable to the ideal efficiency of a tandem cell $(\sim 55 \%)$ with two semiconductors of optimal band gaps (0.7 and $1.5 \mathrm{eV}$ ) [33]. Increasing $\mathrm{x}$ in $\mathrm{Zn}_{0.88} \mathrm{Mn}_{0.12} \mathrm{O}_{\mathrm{x}} \mathrm{Te}_{1-\mathrm{x}}$ to slightly above 0.05 (or $\left.C_{O M}^{2} x \sim 0.24\right)$ would increase the gap between $E_{+}$and $E_{-}$to $1 \mathrm{eV}$ and lead to an optimum power conversion efficiency of $56 \%$. . Also, it is noted that changing the Mn content or replacing Mn with Mg may provide additional ways to vary the band structure for further optimization of solar cell performance. Finally we point out that other quaternary diluted II-VI oxides such as CdMnOTe, $\mathrm{CdMgOTe}$ and $\mathrm{ZnMgOTe}$ are also expected to exhibit multiple absorption edges and therefore are also potential materials for photovoltaic applications

\section{CONCLUSIONS}


We have carried out a systematic investigation of the synthesis and optical properties of the highly mismatched ternary and quaternary II-O-VI alloys. These diluted II-VI oxides are synthesized by $\mathrm{O}$ ion implantation in single crystal II-VI substrates followed by pulsed laser melting. $\mathrm{CdO}_{\mathrm{x}} \mathrm{Te}_{1-\mathrm{x}}$ thin films with $\mathrm{x}$ as high as 0.015 , corresponding to a $150 \mathrm{meV}$ reduction in the fundamental gap are formed. The much reduced band gap corresponds to the transition from the valence band to the lower conduction subband that results from the anticrossing interaction between the localized $\mathrm{O}$ states and the extended conduction states of the matrix. We find that the amount of substitutional $\mathrm{O}$ in $\mathrm{CdTe}$ increases as the implanted $\mathrm{O}$ concentration increases for low doses $(<2 \%)$, but that it saturates as the implanted $\mathrm{O}$ dose increases to above $2 \%$. On the other hand, the band gap energy of samples after PLM at energy fluence higher than 60 $\mathrm{mJ} / \mathrm{cm}^{2}$ shows no dependence on the total implanted $\mathrm{O}$ concentration. Increasing the laser pulse energy fluence reduces the $\mathrm{O}$ incorporation efficiency because of the prolonged duration of the melt/crystallization process. Quaternary $\mathrm{Cd}_{0.6} \mathrm{Mn}_{0.4} \mathrm{O}_{\mathrm{x}} \mathrm{Te}_{1-\mathrm{x}}$ and $\mathrm{Zn}_{0.88} \mathrm{Mn}_{0.12} \mathrm{O}_{\mathrm{x}} \mathrm{Te}_{1-\mathrm{x}}$ HMAs were also synthesized using $\mathrm{O}^{+}$-implantation and PLM with mole fraction of incorporated $\mathrm{O}$ as high as 0.03 . Optical transitions corresponding to both the lower $\left(E \_\right.$and upper $\left(E_{+}\right)$conduction subbands are clearly observed in these quaternary diluted II-VI oxides, in good agreement with the BAC model. The weak pressure dependence of the $E_{-}$transition confirms the more localized nature of this band. These alloys have a three band structure making them suitable for testing the theoretical predictions of highly-efficient multiband, single-junction photovoltaics.

This work was supported by the Director, Office of Science, Office of Basic Energy Sciences, Division of Materials Sciences and Engineering, of the U. S. Department of Energy under Contract No. DE-AC03-76SF00098. MAS acknowledges support from an NSF Graduate Research Fellowship. 


\section{REFERENCES}

1. For a review see : III-N-V Semiconductor Alloys, special Issue of Semiconductor Science and Technology 17, 741-906, 2002: .

2. M. Weyers, M. Sato and H. Ando, Jpn. J. Appl. Phys. 31, L853 (1992).

3. M. Kondow, K. Uomi, K. Hosomi, and T. Mozume, Jpn. J. Appl. Phys. 33, L1056 (1994).

4. W. G. Bi and C. W. Tu, J. Appl. Phys. 80, 1934 (1996).

5. K. Uesugi, N. Morooka, and I. Suemune, Appl. Phys. Lett. 74, 1254(1999).

6. J. F. Geisz, D. J. Friedman, J. M Olson, S. R. Kurtz, and B. M. Keyes, J. Cryst. Growth 195, 401 (1998).

7. W. Shan, W. Walukiewicz, K. M. Yu, J. Wu, J. W. Ager, E. E. Haller, H. P. Xin, and C. W. Tu, Appl. Phys. Lett. 76, 3251 (2000).

8. K. M. Yu, W. Walukiewicz, W. Shan, J. Wu, J. W. Ager III, E. E. Haller, H. P. Xin, and C. W. Tu, Appl. Phys. Lett.78, 1077 (2001).

9. W. Shan, W. Walukiewicz, J. W. Ager III, E. E. Haller, J. F. Geisz, D. J. Friedman, J. M. Olson, and S. R. Kurtz, Phys. Rev. Lett. 82, 1221(1999).

10. W. Walukiewicz, W. Shan, K. M. Yu, J. W. Ager III, E. E. Haller, I. Miotlowski, M. J. Seong, H. Alawadhi, and A. K. Ramdas, Phys. Rev. Lett. 85, 1552 (2000).

11. J. Wu, W. Shan and W. Walukiewicz, Semi. Sci. Tech., 17, 860 (2002).

12. C. Skierbiszewski, P. Perlin, P. Wišniewski, W. Knap, T. Suski, W. Walukiewicz, W. Shan, K. M. Yu, J.W. Ager, E.E. Haller, J.F. Geisz, and J.M. Olson, Appl. Phys. Lett. 76, 2409 (2000). 
13. K. M. Yu, W. Walukiewicz, W. Shan, J. W. Ager III, J. Wu, E. E. Haller, J. F. Geisz, D. J. Friedman, J. M. Olson, and Sarah R. Kurtz, Phys. Rev. B61, R13337 (2000).

14. K. M. Yu, W. Walukiewicz, W. Shan, J. Wu, J. W. Ager III, E. E. Haller, J. F. Geisz, and M.C. Ridgway, Appl. Phys. Lett. 77, 2858 (2000).

15. K. M. Yu, W. Walukiewicz, J. Wu, D. Mars, D. R Chamberlin M. A. Scarpulla, O. D. Dubon, and J. F. Geisz, , Nature Materials 1, 185 (2002).

16. J. Wu, K. M. Yu, W. Walukiewicz, G. He, E. E. Haller, D. E. Mars, D. R Chamberlin, Phys. Rev. B 68, 195202 (2003).

17. K. M. Yu, W. Walukiewicz, J. Wu, W. Shan, J. Beeman, M. A. Scarpulla, O. D. Dubon, M. C. Ridgway, D. E. Mars, and D. R Chamberlin, Appl. Phys. Lett. 83, 2844 (2003)

18. Y. G. Hong, A. Nishikawa, and C. W. Tu, Appl. Phys. Lett. 83, 5446 (2003).

19. Y. Nabetani, Mater. Res. Soc. Symp. Proc. 744, M3.4 (2003).

20. W. Shan, W. Walukiewicz, J.W. Ager III, K. M. Yu, J. Wu, E. E. Haller, Y. Nabetani, T. Mukawa, Y. Ito, and T. Matsumoto, Appl. Phys. Lett. 83, 299 (2003).

21. K. M. Yu, W. Walukiewicz, J. Wu, J. W. Beeman, J. W. Ager, E. E. Haller, I. Miotkowski, A. K. Ramdas, and P. Becla, Appl. Phys. Lett. 80, 1571 (2002).

22. K. M. Yu, W. Walukiewicz, J. W. Beeman, M. A. Scarpulla, O. Dubon, M. R. Pillai, and M. Aziz, Appl. Phys. Lett. 80, 3958 (2002).

23. K. M. Yu, W. Walukiewicz, M. A. Scarpulla, O. D. Dubon, J. Jasinski, Z. LilientalWeber, J. Wu, J. W. Beeman, M. R. Pillai, and M. J. Aziz, J. Appl. Phys.94, 1043 (2003). 
24. K. M. Yu, W. Walukiewicz, J. Wu, J. W. Beeman, J. W. Ager III, E. E. Haller, W. Shan, H. P. Xin, C. W. Tu, and M. C. Ridgway, J. Appl. Phys. 90, 2227 (2001).

25. C. W. White and P. S. Peercy, eds., Laser and Electron Beam Processing of Materials (Academic Press, New York, 1980).

26. J. S. Williams in Laser Annealing of Semiconductors, J. M. Poate and J. W. Mayer, eds., p. 385 (Academic Press, New York, 1982).

27. M. A. Scarpulla, K.M. Yu, O. Monteiro, M. Pillai, M.C. Ridgway, M.J. Aziz, and O.D. Dubon, Appl. Phys. Lett. 82, 1251 (2003).

28. D. E. Aspnes, Surf. Sci. 37, 418 (1973).

29. J. Jasinski, K. M. Yu, W. Walukiewicz, Z. Liliental-Weber and J. Washburn, Appl. Phys. Lett. 79, 931 (2001).

30. V. A. Gnatyuk, T. Aoki, O. S. Gorodnychenko, Y. Hatanaka, Appl. Phys. Lett. 83, 307704 (2003).

31. M. J. Seong, H. Alawadhi, I. Miotkowski, A. K. Ramdas and S. Miotkowska, Phys. Rev. B 60, R16275(1999).

32. K. M. Yu, W. Walukiewicz, J. Wu, W. Shan, and J. W. Beeman, M. A. Scarpulla, O. D. Dubon, and P. Becla, Phys. Rev. Lett. 91, 246203 (2003).

33. A. Luque, and A.Marti, Phys. Rev. Lett., 78, 5014-5017 (1997).

34. A. S.Brown, , M. A. Green, and R. P. Corkish, Physica E 14, 121-125, (2002).

35. W. Shockley and H. J. Queisser,. J. Appl. Phys. 32, 510 (1961). 


\section{FIGURE CAPTIONS}

Fig. 1 A series of photoreflectance (PR) spectra from CdTe samples unimplanted and implanted with 4 mole $\%$ of $\mathrm{O}$ followed by rapid thermal annealing in the temperature range of $300-500^{\circ} \mathrm{C}$ for $10 \mathrm{~s}$.

Fig. 2 PR spectra of $\mathrm{O}^{+}$-implanted CdTe samples followed by PLM with an energy fluence of $40 \mathrm{~mJ} / \mathrm{cm}^{2}$. The samples were implanted with $\mathrm{O}$ with total dose corresponding to 0 to 4 mole $\%$ of $\mathrm{O}$ in CdTe.

Fig. 3 The band gap energies of the $\mathrm{CdO}_{\mathrm{x}} \mathrm{Te}_{1-\mathrm{x}}$ alloys formed by $\mathrm{O}^{+}$-implantation in CdTe followed by PLM with laser energy fluence in the range of 40 to 100 $\mathrm{mJ} / \mathrm{cm}^{2}$ as a function of implanted $\mathrm{O}^{+}$concentration.

Fig. 4 The "active" $\mathrm{O}$ mole fractions incorporated in the Te sublattice for $\mathrm{CdO}_{\mathrm{x}} \mathrm{Te}_{1-\mathrm{x}}$ HMAs synthesized by ion implantation followed by PLM using laser fluence of 40 and $80 \mathrm{~mJ} / \mathrm{cm}^{2}$ as a function of implanted $\mathrm{O}$ concentration. The $\mathrm{x}$ values are calculated according to the band anticrossing model [Eq. (1)] using an assumed interaction parameter $C_{O M}=2.2 \mathrm{eV}$.

Fig. 5 PR spectra from the $2 \% \mathrm{O}^{+}$-implanted CdTe samples after PLM with $40 \mathrm{~mJ} / \mathrm{cm}^{2}$ followed by RTA for $10 \mathrm{~s}$ at temperatures of 300 and $400^{\circ} \mathrm{C}$.

Fig. 6 PR spectra of two $\mathrm{O}^{+}$-implanted $\mathrm{Cd}_{1-\mathrm{y}} \mathrm{Mn}_{\mathrm{y}}$ Te samples with $\mathrm{y}=0$ and 40, respectively followed by PLM. PR spectra of the original $\mathrm{Cd}_{1-\mathrm{y}} \mathrm{Mn}_{\mathrm{y}} \mathrm{Te}$ substrates are also shown for comparison.

Fig. 7 PR spectra of $\mathrm{Cd}_{0.6} \mathrm{Mn}_{0.4} \mathrm{O}_{\mathrm{x}} \mathrm{Te}_{1-\mathrm{x}}$ layers formed by $\mathrm{O}^{+}$-implantation followed by RTA and PLM, respectively. PR spectra of the as-grown $\mathrm{Cd}_{0.6} \mathrm{Mn}_{0.4}$ Te substrates are shown in dotted lines. 
Fig. 8 PR spectra obtained from a series of $3.3 \% \mathrm{O}^{+}$-implanted $\mathrm{Zn}_{0.88} \mathrm{Mn}_{0.12}$ Te samples followed by PLM with increasing energy fluence from $0.04-0.3 \mathrm{~J} / \mathrm{cm}^{2}$. The PR spectrum from an as-grown $\mathrm{Zn}_{0.88} \mathrm{Mn}_{0.12}$ Te crystal is also shown for comparison.

Fig. 9 The energy positions of $\mathrm{E}_{-}$and $\mathrm{E}_{+}$for the $\mathrm{Zn}_{0.88} \mathrm{Mn}_{0.12} \mathrm{O}_{x} \mathrm{Te}_{1-x}$ alloys plotted against the $\mathrm{O}$ mole fraction $\mathrm{x}$. The values of $\mathrm{E}_{-}$and $\mathrm{E}_{+}$calculated according to the band anticrossing model are plotted as solid lines.

Fig. 10 Effect of pressure on the energy position of the E_ band edge of a $\mathrm{Zn}_{0.88} \mathrm{Mn}_{0.12} \mathrm{O}_{\mathrm{x}} \mathrm{Te}_{1-\mathrm{x}}$ sample (triangles). The change of the band gap of the $\mathrm{Zn}_{0.88} \mathrm{Mn}_{0.12} \mathrm{Te}$ substrate with pressure is also displayed (open circle). The solid lines are theoretical fitting results. The dashed-dotted line is the location of $\mathrm{E}_{\mathrm{O}}$ relative to the top of the valence band. The inset shows a typical photomodulated transmission (PT) spectrum of $\mathrm{Zn}_{0.88} \mathrm{Mn}_{0.12} \mathrm{O}_{\mathrm{x}} \mathrm{Te}_{1-\mathrm{x}}$ under pressure. 


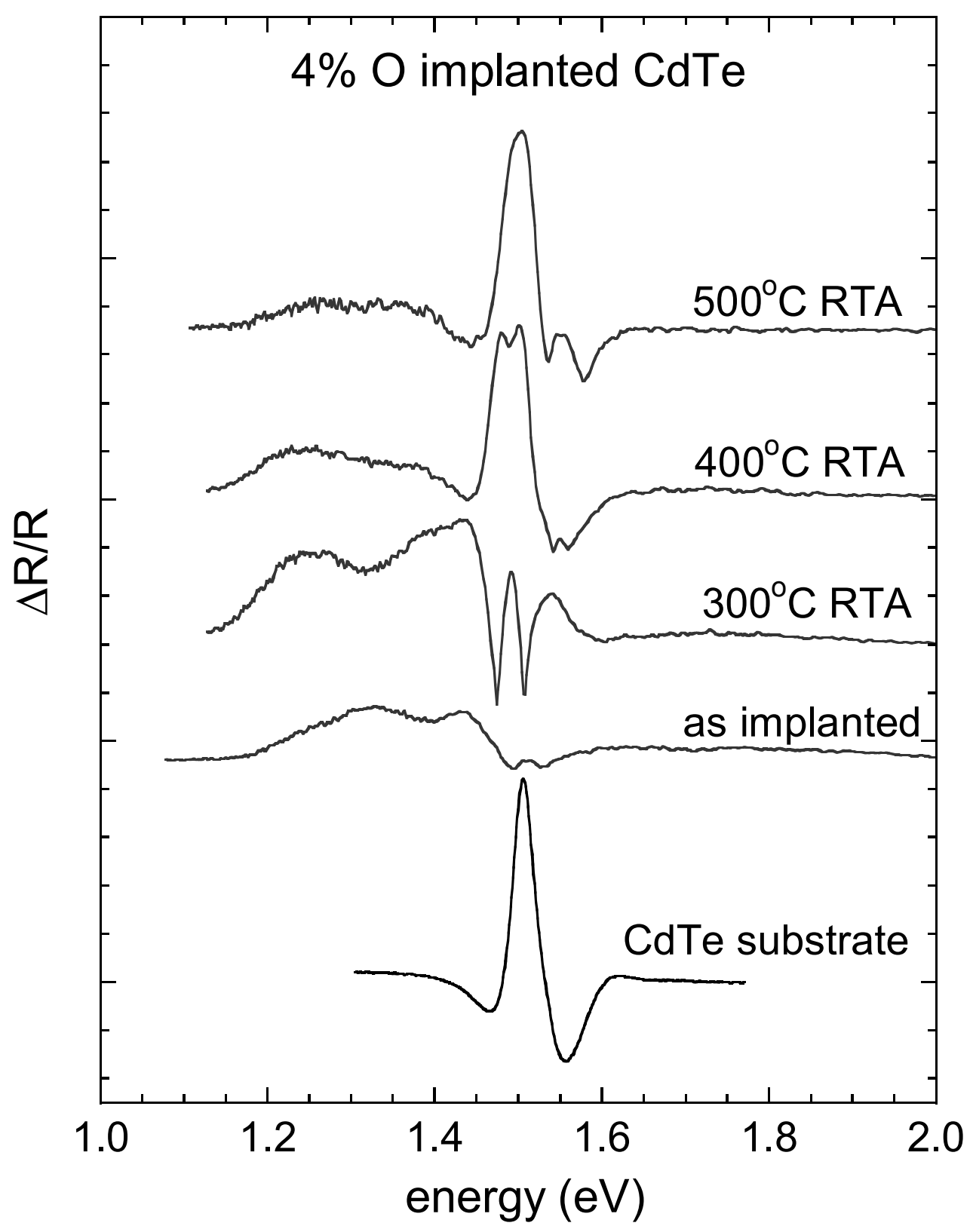

Fig. 1 


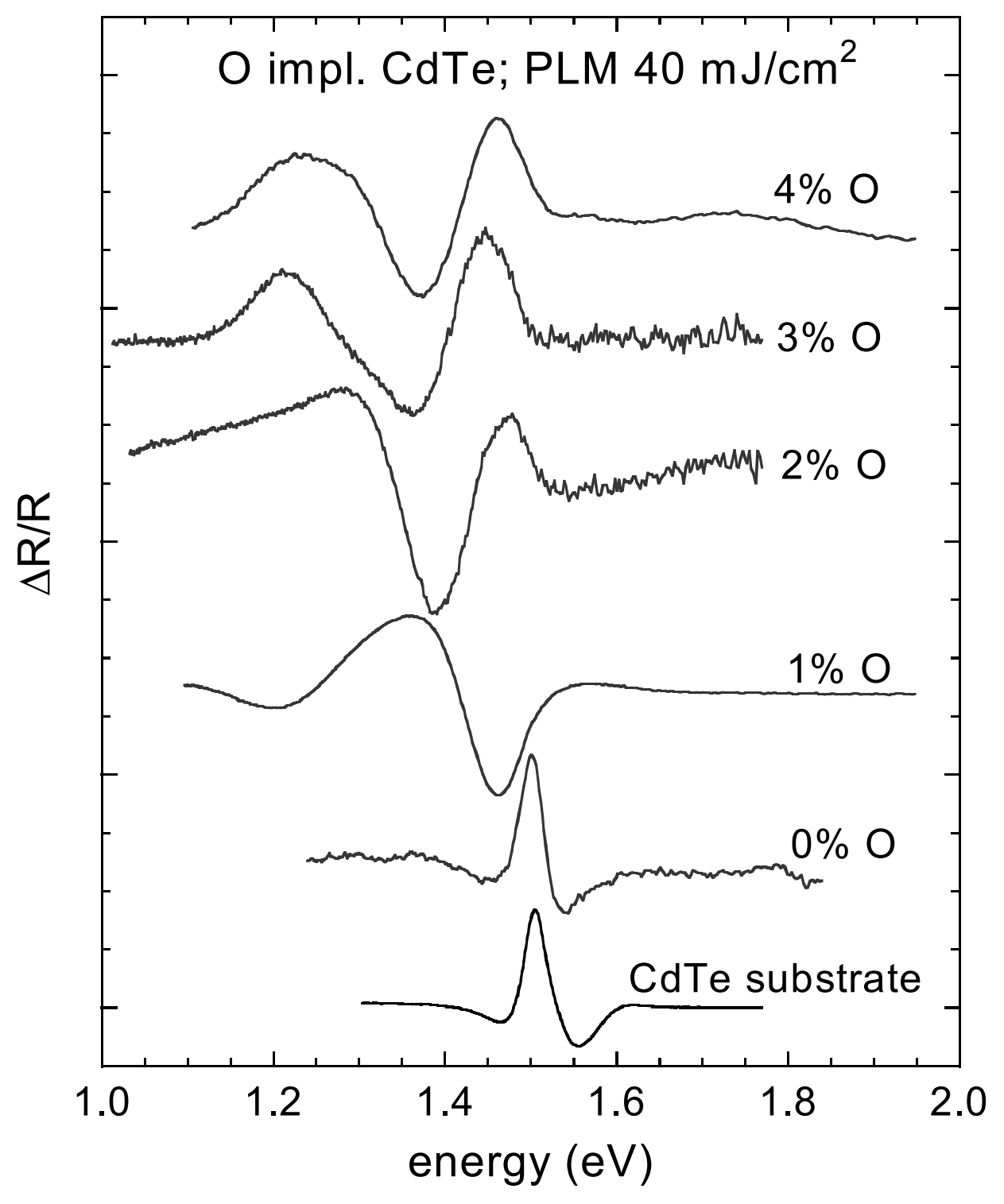

Fig. 2 


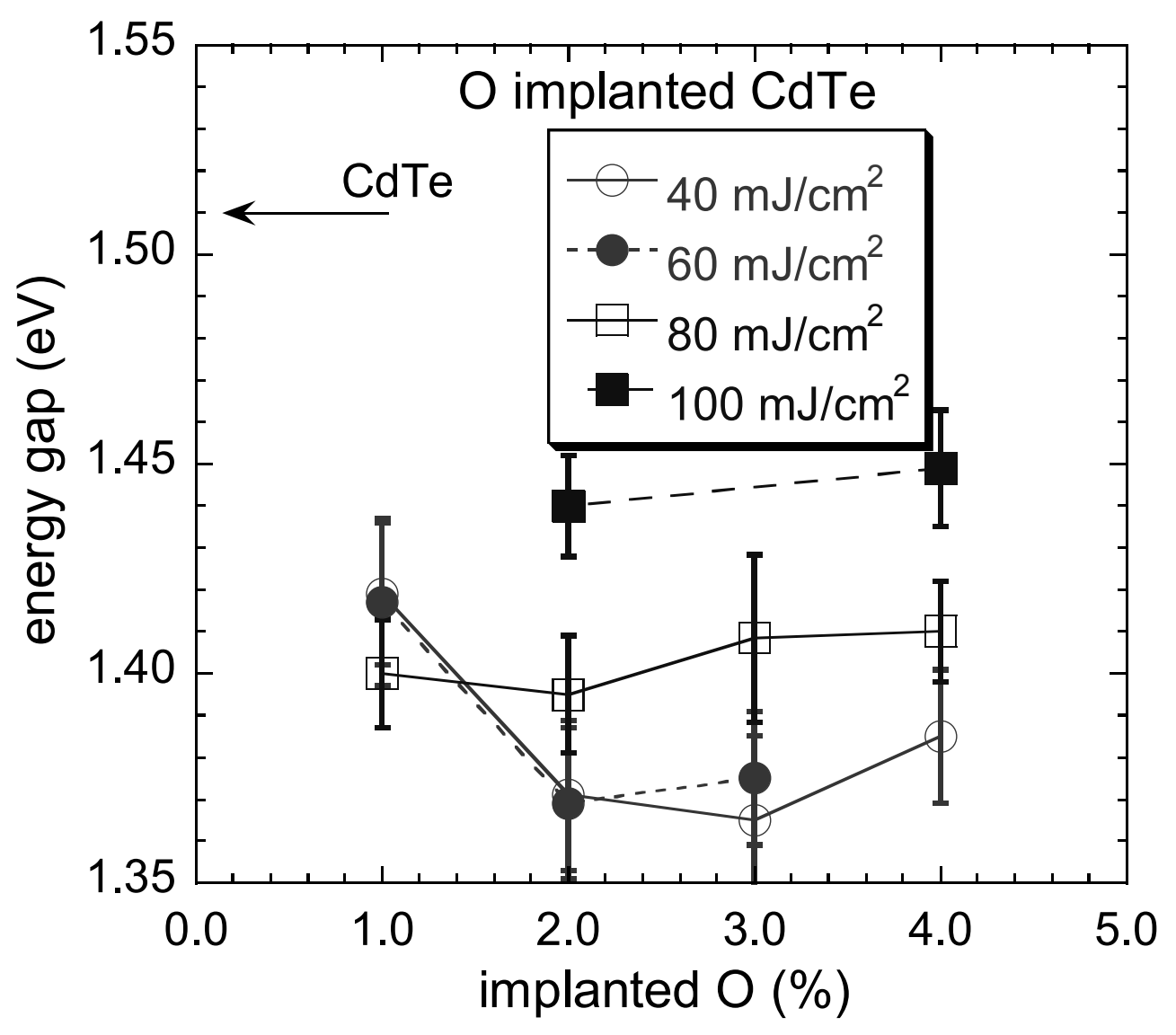

Fig. 3 


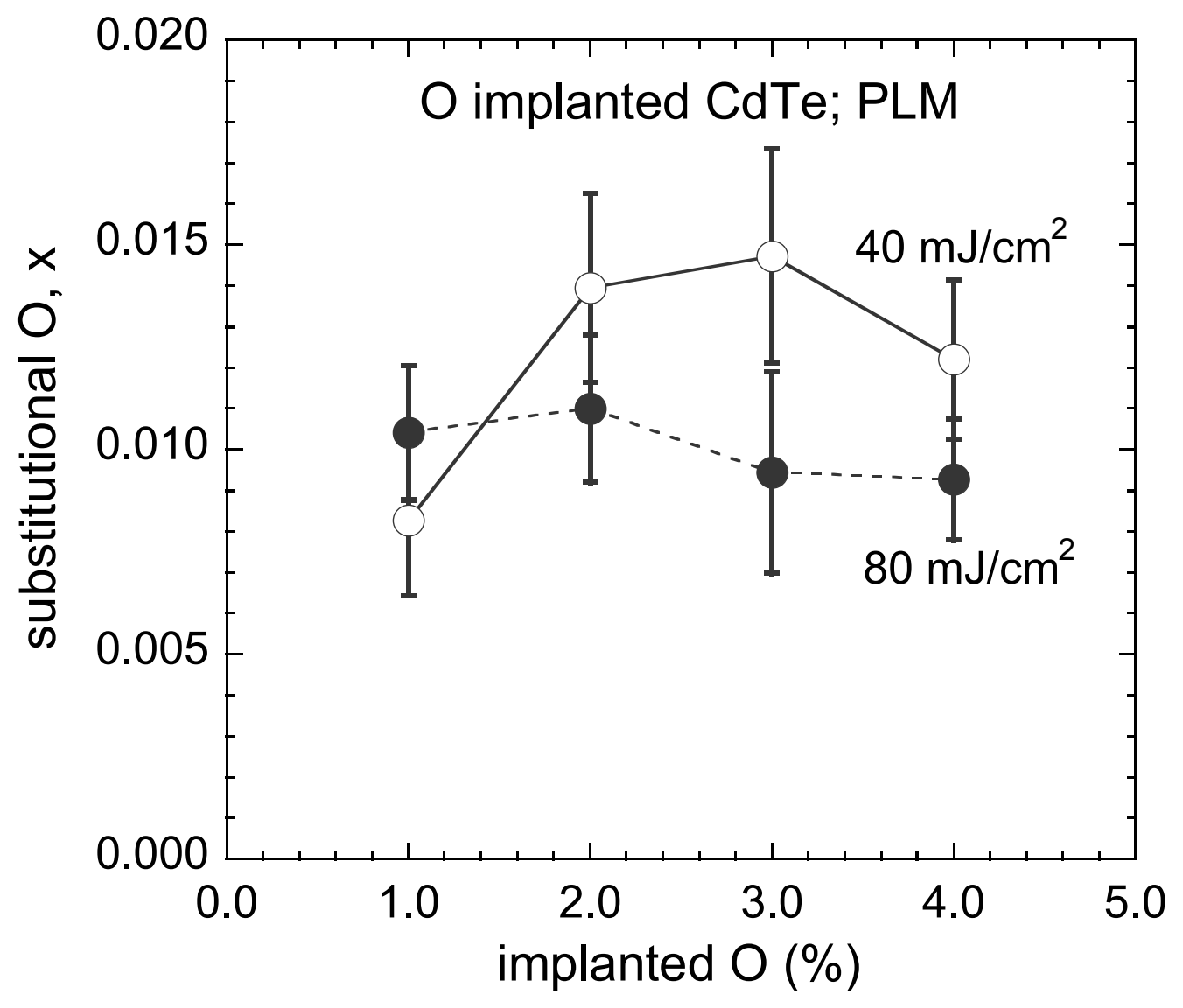

Fig. 4 


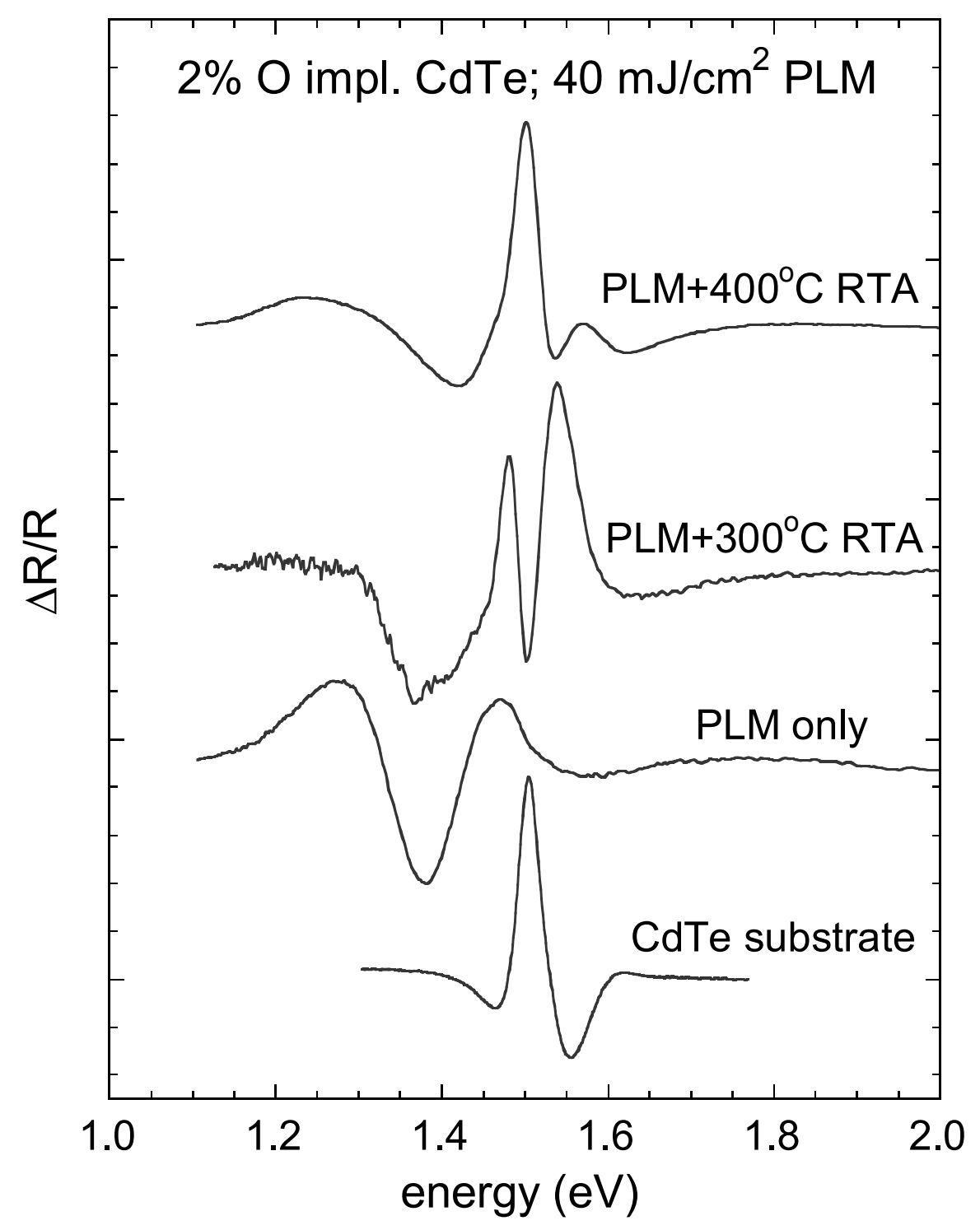

Fig. 5 




Fig. 6 


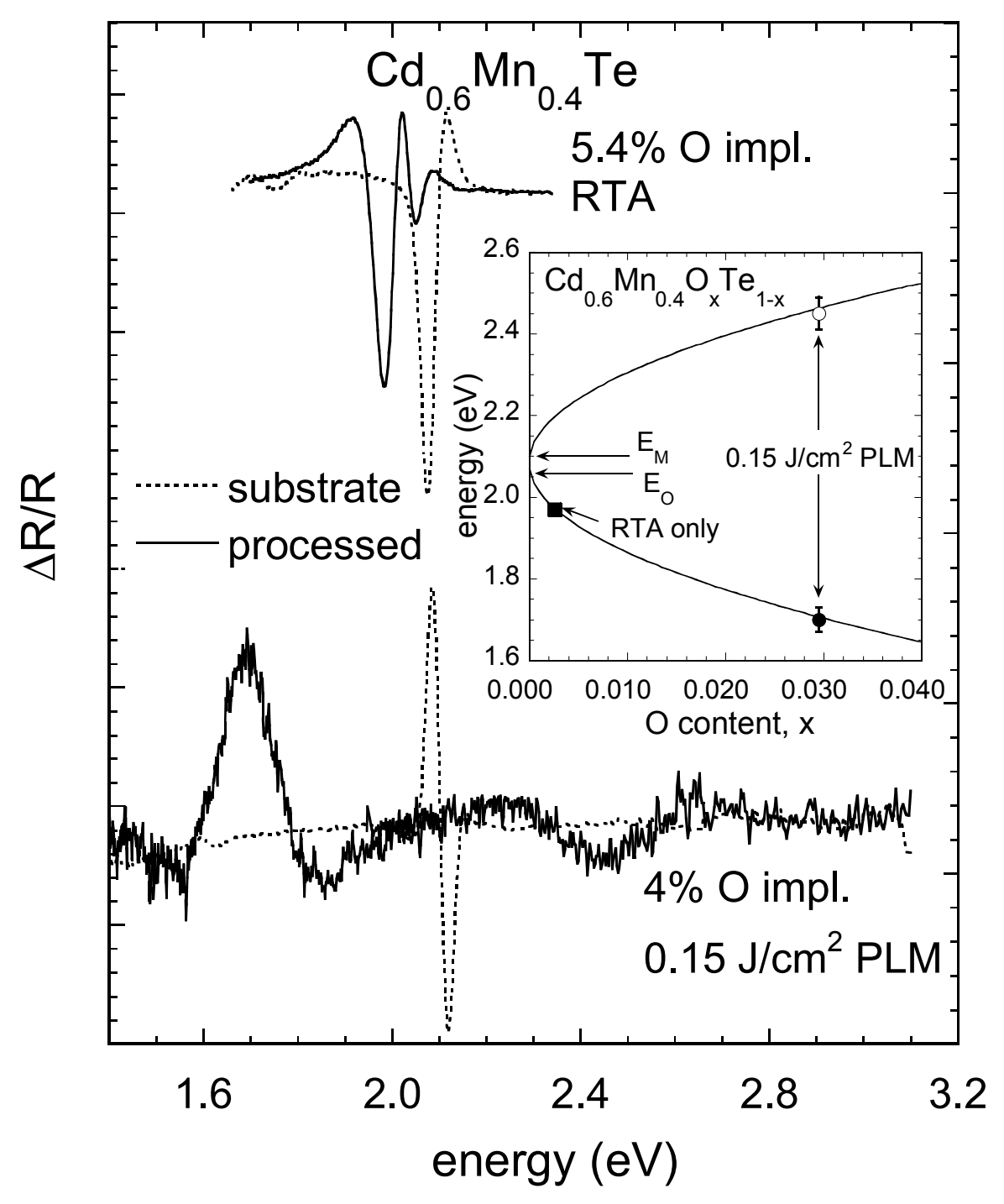

Fig. 7 


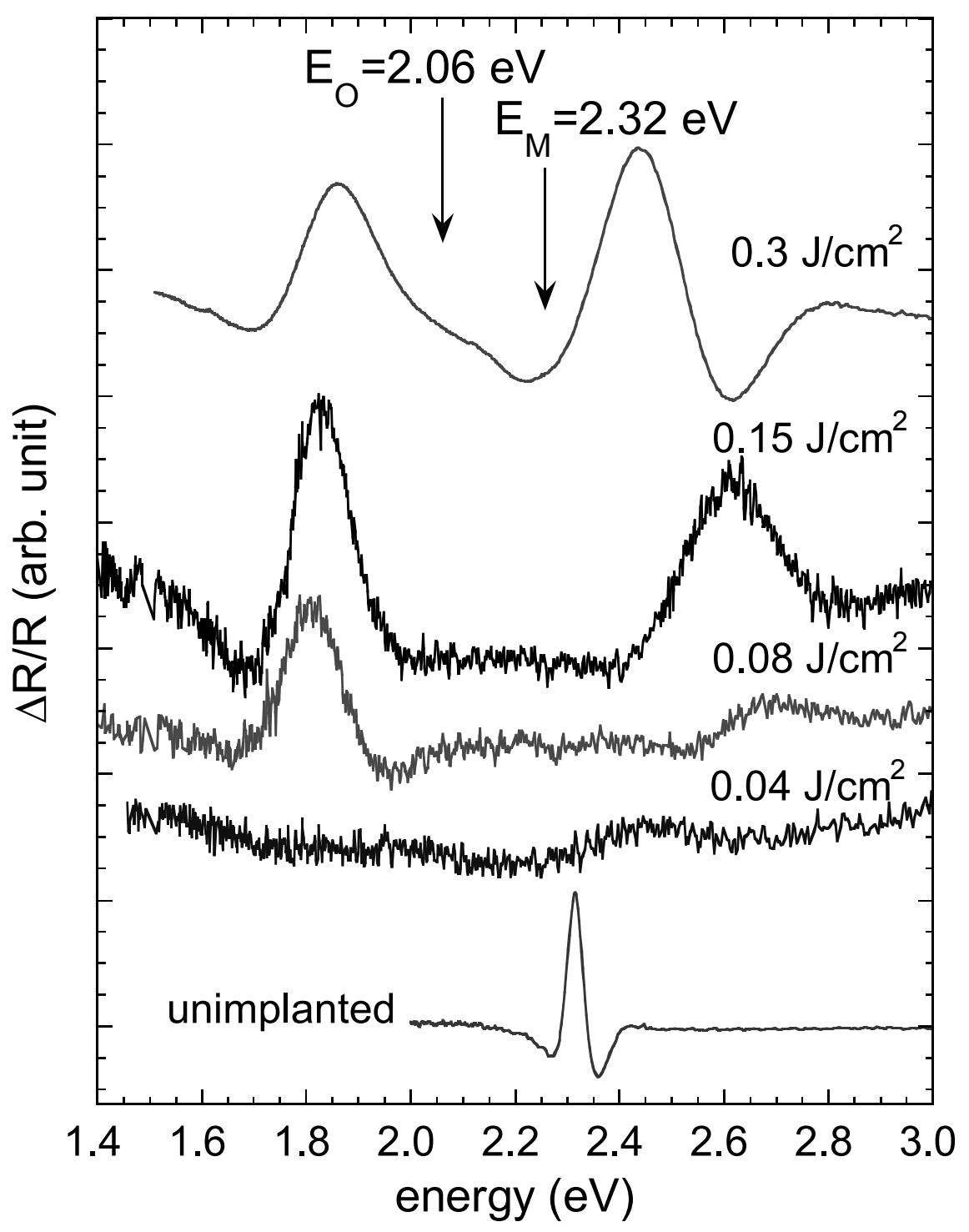

Fig. 8 


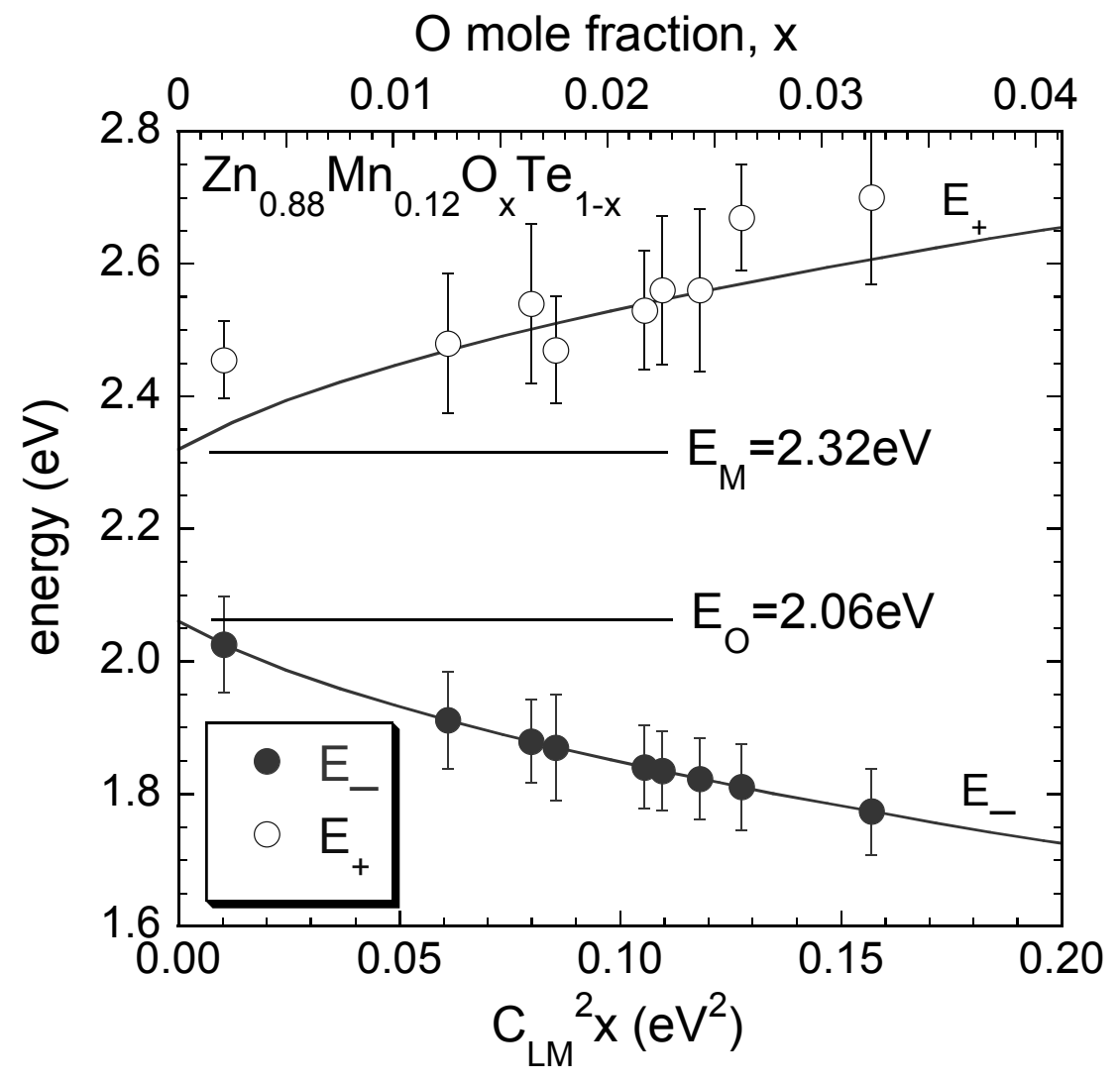

Fig. 9 


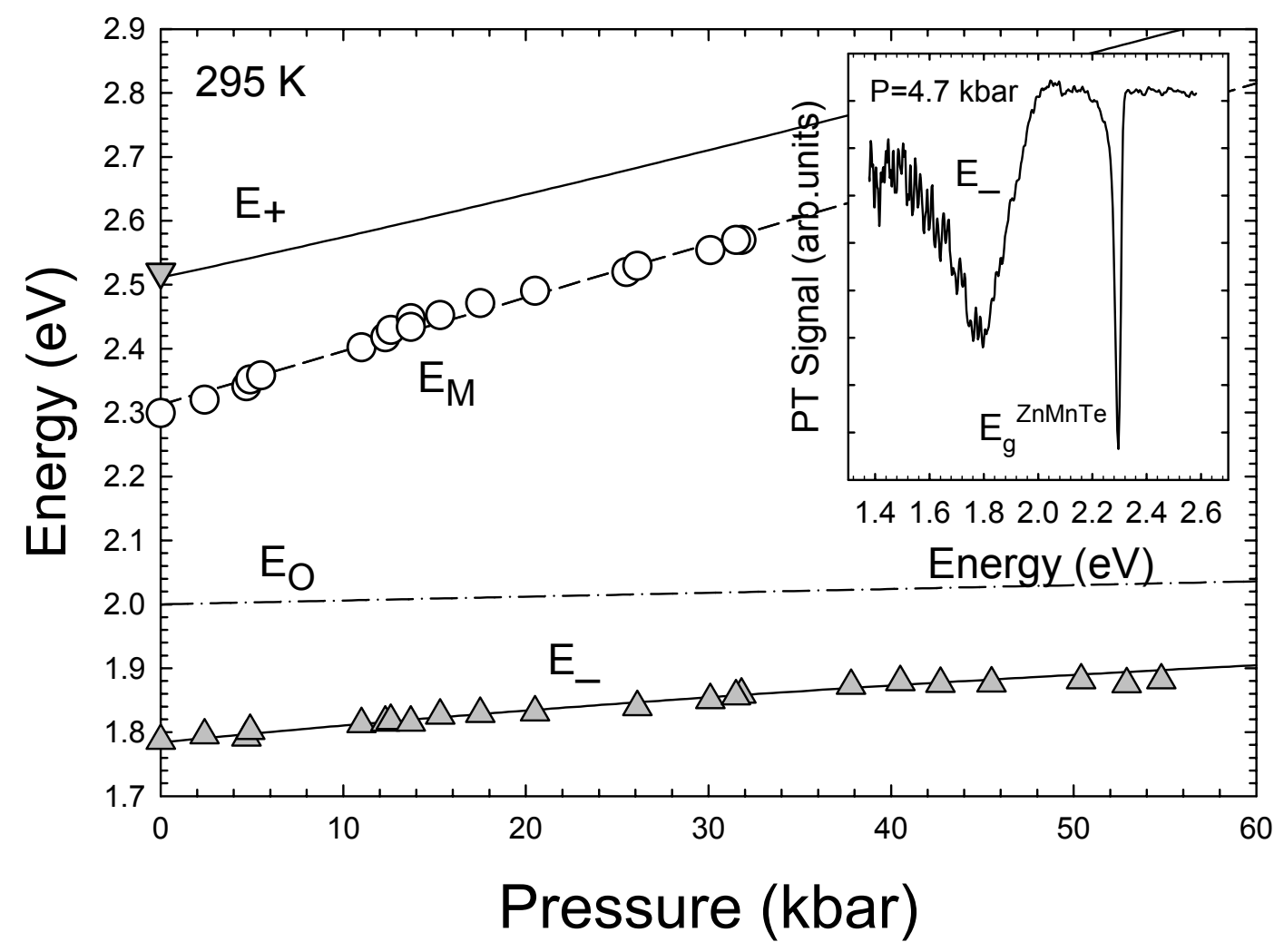

Fig. 10 